\title{
Aplikasi Metode Tasmi' Dan Muraja'ah Dalam Program Tahfidzul Quran Pada Santriwati di Ma'had Tahfidz Hidayatul Qur'an Desa Puding Besar
}

\author{
Wiwik Hendrawati' ${ }^{1}$ Rosidi $^{2}$, Sumar ${ }^{3}$ \\ ${ }^{1}$ IAIN Syaikh Abdurrahman Siddik Bangka Belitung \\ 2 IAIN Syaikh Abdurrahman Siddik Bangka Belitung \\ 3 IAIN Syaikh Abdurrahman Siddik Bangka Belitung
}

Info Artikel :

Diterima 3 Januari 2020

Direvisi 12 Januari 2020

publikasikan 22 Januari2020

\section{Kata Kunci:}

Metode Tasmi'

Muraja'ah

Tahfidzul Qur'an.
Keywords:

Tasmi Method'

Muraja'ah

Tahfidzul Qur'an.

\section{Koresponden:}

Wiwik Hendrawati

Email: Wiwikpd55@gmail.com

\begin{abstract}
ABSTRAK
Penelitian ini bertujuan untuk mengetahui penerapan metode tasmi' dan muraja'ah dalam program tahfidzul Qur'an pada santriwati di Ma'had Tahfidz Hidayatul Qur'an Desa Puding Besar dan untuk mengetahui keberhasilan program tahfidzul qur'an dengan menggunakan metode tasmi' dan muraja'ah pada santriwati di Ma'had Tahfidz Hidayatul Qur'an Desa Puding Besar. Metode penelitian ialah kualitatif deskriptif, sedangkan sumber data yang digunakan ada dua sumber yaitu, data primer dan sekunder. Tekhnik pengumpulan data dalam penelitian dilakukan melalui observasi, wawancara, dan dokumentasi. Penerapan metode tasmi' di Ma'had Tahfidz Hidayatul Qur'an Desa Puding Besar berhasil diterapkan. Hal ini dapat dilihat dari banyaknya santriwati yang hafal dan mencapai target yang ditentukan, bahkan ada yang melebihi pencapaian target. Begitu pula dengan metode muraja'ah santriwati mampu mentasmi'kan kembali hafalan muraja'ah baik kepada ustadzah pembimbing atau ustadzah penguji ujian tahfidz. Hal ini terbukti dari hasil yang diperoleh santriwati dengan kategori penilaian mumtaz (kesalahan 0-1), jayyid jiddan (kesalahan 2-4), jayyid (kesalahan 5-7), maqbul (kesalahan 8-10), rasib (kesalahan lebih dari sepeluh), dari kelima penilaian tersebut kebanyakan santriwati mendapatkan nilai jayyid jiddan, jayyid, dan mumtaz.
\end{abstract}

\section{ABSTRACT}

This study aims to determine the application of the tasmi 'and muraja'ah methods in the tahfidzul Qur'an program for female students in Ma'had Tahfidz Hidayatul Qur'an Puding Besar Village and to determine the success of the tahfidzul qur'an program using the tasmi' and muraja 'methods ah to the students at Ma'had Tahfidz Hidayatul Qur'an, Puding Besar Village. The approach used in this research is descriptive qualitative, while the sources of data used are two sources, namely, primary and secondary data. Data collection techniques in research carried out through observation, interviews, and documentation. The application of the tasmi method in Ma'had Tahfidz Hidayatul Qur'an of Puding Besar Village was successfully implemented. This can be seen from the number of female students who memorized and reached the specified target, some even exceeded the target achievement. Similarly, the method of muraja'ah santriwati was able to eradicate the memorization of muraja'ah both to the cleric or the cleric examiner tahfidz. This is evident from the results obtained by female students in the category of mumtaz (error 0-1), jayyid jiddan (error 2-4), jayyid (error 5-7), maqbul (error 8-10), rasib (error more than ten) ), from the five assessments, most students received jayyid jiddan, jayyid, and mumtaz.

This is an open access article distributed under the Creative Commons Attribution License, which permits unrestricted use, distribution, and reproduction in any medium, provided the original work is properly cited. @2019 by author. 


\section{Pendahuluan}

Alquran adalah kalam Allah yang bernilai mukjizat, yang diturunkan kepada Nabi Muhammad sallallahu 'alaihi wa sallam, dengan perantara malaikat Jibril, diriwayatkan kepada kita dengan mutawwatir, membacanya terhitung sebagai ibadah dan tidak akan ditolak kebenarannya. ${ }^{1}$ Alquran bagi umat Islam merupakan sesuatu yang sangat istimewa sehingga begitu mudah untuk dihafal, dari usia balita hingga usia senja dijamin mampu menghafalkannya. Kemudahan menghafal Alquran memang begitu mempesona hingga tidak mampu dibatasi sekat logika. Seorang tunanetra mampu menghafalkannya bahkan manula tuna aksara begitu mudah menghafalkannya. ${ }^{2}$ Meskipun Alquran itu mudah untuk dihafal, namun untuk meraih keutamaan itu tidak mudah, karena menghafal Alquran memerlukan proses yang cukup lama dan tidak semudah membalikkan telapak tangan karena setiap orang memiliki cara atau metode sendiri dalam menghafal. Meski demikian, metode yang paling banyak digunakan adalah yang cocok dan menyenangkan bagi setiap individu. Jika diteliti, kebanyakan metode yang cocok bagi setiap orang diperoleh melalui beberapa kali percobaan.

Di Ma'had Tahfidz Hidayatul Qur'an Desa Puding Besar menerapkan beberapa metode dalam memudahkan santriwati dalam menghafal Alquran yaitu bin-nadzar, takrir, tahfidz, tasmi' dan muraja'ah. Ustadzah Laila, salah satu ustadzah di Ma'had Tahfidz Hidayatul Qur'an menyebutkan dalam wawancaranya, metode menghafal yang diterapkan ialah metode tasmi' dan muraja'ah. ${ }^{3}$ Karena menghafal Alquran harus langsung bertatap muka dengan guru agar bisa diketahui kesalahan dalam membaca Alquran. Metode muraja'ah juga sangat penting dalam menghafal, karena hafalan jika tidak dimuraja'ahkan akan hilang. Sebagaimana yang dikatakan bahwa menghafal tidak semudah membalikkan telapak tangan namun juga tidak sulit jika ada kemauan. Maka Ma'had Tahfidz Hidayatul Qur'an menerapkan metode tersebut untuk memudahkan santriwati menghafal serta mengejar target hafalan pertahunnya. ${ }^{4}$ Dengan menggunakan metode tasmi' dan muraja'ah santriwati bisa mengejar target hafalan setiap tahunnya bahkan ada yang sudah menyelesaikan hafalannya 30 juz dalam waktu yang sama, dengan hasil yang baik.

Berdasarkan latar belakang masalah yang telah diuraikan diatas, maka peneliti tertarik untuk melakukan penelitian tentang Penerapan Metode Tasmi' dan Muraja'ah dalam Program Tahfidzul Qur'an pada santriwati Ma'had Tahfiz Hidayatul Qur'an Desa Puding Besar.

\section{Metode Tasmi'}

Tasmi' yaitu mensetorkan hafalan secara rutin kepada muhafidz atau kepada seorang yang menyimaknya dengan mushaf. Men-tasmi'kan akan menumbuhkan rasa yakin dengan apa yang telah dihafal. ${ }^{5}$ Menurut Sa'dullah, tasmi' ialah memperdengarkan hafalan kepada orang lain baik kepada perseorangan maupun kepada jamaah. ${ }^{6}$

Dengan tasmi' seseorang akan lebih konsentrasi dalam hafalan. Sebagaimana yang dikatakan oleh Wiwi Alawiyah Wahid bahwa setiap santri diharuskan untuk memperdengarkan hafalannya kepada guru atau kyai agar bisa diketahui letak kesalahan ayat-ayat yang dihafal.

a. Langkah-Langkah Metode Tasmi'.

Terdapat beberapa langkah saat hendak men-tasmi'kan hafalan Alquran yaitu sebagai berikut:

1) Penyimakan perorangan.

Seorang hafidz membaca hafalan dari juz 1 sampai 30 dan disimak oleh sejumlah orang. Metode ini sering dipakai oleh seorang hafidz yang telah lancar hafalannya baik perorangan maupun berjama'ah tujuannya agar penghafal qur'an bisa diketahui letak kekurangan dalam menghafal Alquran baik dari segi pengucapan huruf maupun tajwidnya. ${ }^{7}$

2) Penyimakan keluarga.

\footnotetext{
${ }^{1}$ Ahsin W. AlHafidz, Bimbingan Praktis Menghafal Alquran,(Jakarta: Bumi Aksara, 2000), hlm. 1.

${ }^{2}$ Adi Hidayat, Muslim Zaman Now, 30 hari hafal Alquran Metode At Taisir..., hlm xv.

${ }^{3}$ Lailatul Mardiah, Pembimbing Tahfidz Ma'had Tahfidz Hidayatul Qur'an Desa Puding Besar, Wawancara Tanggal 20 November 2019.

${ }^{4}$ Lailatul Mardiah, Pembimbing Tahfidz Ma'had Tahfidz Hidayatul Qur'an Desa Puding Besar, Wawancara Tanggal 20 November 2019.

${ }^{5}$ Romdoni Massul, Metode Cepat Menghafal \& Memahami Ayat-Ayat Suci Alquran, (Yogyakarta: Lafal Indonesia, 2014), hlm. 49.

${ }^{6}$ Sa'dulloh, 9 Cara Praktis Menghafal Alquran..., hlm. 54.

${ }^{7}$ Raisya Maulana Ibnu Rusyd, Panduan Praktis dan Lengkap Tahsin, Tajwid, Tahfidz untuk Pemula, (Yogyakarta: Laksana, 2019), hlm. 202.
} 
Penyimakan keluarga hampir sama dengan penyimakan perorangan. Dalam hal ini penyimak adalah anggota keluarga dan tidak seluruh ayat Alquran dibaca habis dalam satu majlis. Waktu dan jumlah materi yang disimak pun bisa disepakati.

3) Penyimakan dua orang .

Metode ini dilaksanakan secara bergantian antara dua orang atau lebih. Ketika ada yang membaca maka yang lain diam untuk menyimak, baik dengan melihat mushaf ataupun tidak.

4) Tasmi' dengan sesama teman tahfidz.

Dilakukan kepada sesama teman tahfidz sebelum ditasmi'kan kepada seorang guru. Metode ini pun dilakukan oleh Rasulullah Sallallahu 'Alaihi Wasallam bersama malaikat Jibril dengan tujuan agar wahyu yang telah diturunkan oleh Allah melalui malaikat Jibril tidak ada yang berkurang atau berubah. ${ }^{8}$

5) Penyimakan kelompok.

Penyimakan kelompok dilakukan oleh sejumlah hafidz, misalnya 30 orang dibagi menjadi tiga kelompok. Masing-masing terdiri atas 10 orang. Kelompok pertama membaca juz 1 sampai juz 10, kelompok kedua membaca juz 11 sampai juz 20, dan kelompok ketiga membaca juz 21 samapai 30. Setiap orang membaca satu juz secara bergiliran hingga selesai. Ketika ada seseorang membaca maka lainnya menyimak. ${ }^{9}$

6) Menyimakkan kepada ustadz/ustadzah.

Ketika santriwati sudah benar-benar siap dengan hafalannya maka segera men-tasmi'kan hafalannya kepada ustadzah pembimbing pada jam tahfidz atau dilain waktu. ${ }^{10}$

b. Manfaat metode sima'an bagi para hafidz maupun hafidzah sebagai berikut:

1) Termotivasi untuk lebih giat menghafal.

Dengan mengikuti kegiatan sima'an penghafal tidak akan mudah lelah dan jenuh untuk mengulang-ulang hafalan selain itu juga dapat mengukur kualitas hafalan yang dimiliki.

2) Menghilangkan kerancuan pada ayat-ayat mutasyabihat.

Tekhnik paling utama untuk menghafal ayat-ayat mutasyabihat sehingga fokus pada otak anda ialah dengan memperdengarkan hafalan kepada seorang guru ngaji yang profesional atau spesialis ayat-ayat mutasyabihat. ${ }^{11}$

3) Memelihara hafalan supaya tetap terjaga.

Alquran adalah amanah dan anugerah yang harus dijaga. Sebagai penghafal Alquran harus senantiasa menjaga hafalan Alquran dan mempelajarinya secara continue, serta mengamalkan isinya karena Alquran sifatnya lebih mudah hilang dari ingatan di banding seekor hewan yang ditambatkan, lalu di tinggalkan begitu saja tanpa di awasi. ${ }^{12}$

4) Menghilangkan rasa gugup ketika membaca Alquran.

Rasa gugup, adalah perasaan alami manusia yang diberikan Allah agar tidak terlalu percaya diri dan akhirnya sombong. Untuk menghilangkan rasa gugup perlu latihan. Salah satunya dengan mengikuti kegiatan sema'an untuk melatih agar percaya diri.

5) Melatih diri agar tidak tergesa-gesa dalam membaca Alquran.

Sesungguhnya menghafal Alquran merupakan tingkat tertinggi didalam surga.

6) Cepat menguasai bacaan Alquran dengan benar.

Mempunyai pasangan sima'an sangat membantu penghafal dalam proses melancarkan dan menguatkan hafalan. Hal ni dilakukan sebagai proses saling mengoreksi satu sama lain agar letak kesalahan yang terjadi bisa terdeteksi.

7) Konsep Metode Sema'an Alquran.

Ayat-ayat Alquran hanya akan tetap bersemayam didalam hati untuk al'ilm jika ayat-ayat yang dihafal selalu diingat dan diulang-ulang.

\section{Metode Muraja'ah}

\section{a. Pengertian Muraja'ah}

100.

${ }^{8}$ Wiwi Alawiyah Wahid, Cara Cepat Bisa Menghafal Alquran, (Jogjakarta: Diva Press, 2014), hlm. 99-

${ }^{9}$ Ulin Nuha Mahfudhon, Jalan Penghafal Alquran, (Jakarta: Kompas Gramedia, 2017), hlm. 117-118.

10 Wiwi Alawiyah Wahid, Cara Cepat Bisa Menghafal Alquran.., hlm. 101.

${ }^{11}$ Yahya bin 'Abdurrazaq Al-Ghausani, Metode Cepat Hafal Alquran, (Sukoharjo: As-Salam, 2016), hlm.

${ }^{12}$ Mukhlisoh Zawawie, PM3 Alquran Pedoman Membaca, Mendengar, dan Menghafal Alquran. (Solo: Tinta Medina, 2011), hlm. 113-114. 
Muraja'ah yaitu mengulang-ulang hafalan. Muraja'ah tidak terpisah dari kegiatan menghafal, karena setelah menghafal, tugas selanjutnya ialah mengulang hafalan yang sudah dihafal untuk menjaga dari lupa dan salah. ${ }^{13}$ Waktu yang terbaik untuk muraja'ah ialah dalam setiap kesempatan. ${ }^{14}$ Muraja'ah hafalan bisa dilakukan dengan sendiri, memperdengarkan kepada guru dan teman.

Pada umumnya, seorang guru membagi waktu kegiatan menyetor hafalan Alquran. Waktu pagi, digunakan untuk menyetor hafalan baru, dan waktu sore setelah Asar atau setelah maghrib dimanfaatkan untuk menyetor hafalan lama. ${ }^{15}$ didalam bukunya Dr. KH. Rachmat Morado Sugiarto, ada beberapa metode dalam mengulang hafalan sesuai dengan pengalaman penulis yaitu:

1) Mengulang hafalan dalam sholat.

Dalam hal ini, yang dibaca bukan hanya surah pendek saja, melainkan semua surah yang sudah dihafal. Baik dalam sholat fardhu ataupun sunnah. Sebagaimana yang telah dilakukan oleh Rasulullah Sallahu 'Alaihi Wasallam beliau selalu mengulang hafalannya dalam sholat sunnah tahajjud lebih dari 6 juz. Maka seorang penghafal hendaklah mencontohi Rasulullah Sallallahu 'Alaihi Wasallam agar hafalan semakin kuat dan kokoh.

2) Mengulang hafalan dengan ditulis.

Metode ini dilakukan sebagai upaya untuk mengingat kembali hafalan bukan hanya dengan lisan akan tetapi dengan tulisan. Metode ini didasari dengan pemikiran bahwa ilmu itu perlu ditulis. Sebagaimana yang diriwayatkan oleh Ath Tahbrani dalam Al Awsath yaitu ikatlah ilmu dengan tulisan. ${ }^{16}$

3) Mengulang hafalan dengan membaca bersama-sama.

Para penghafal Alquran baik perkelas atau perangkatan mengulang hafalannya bersama dengan membaca surah dan ayat yang sama.

4) Mengulang Alquran dengan metode tasmi'.

Tasmi' artinya memperdengarkan bacaan Alquran. Men-tasmi'kan hafalan bisa dilakukan kepada guru atau teman yang sudah kuat hafalannya. Metode ini sangat membantu dalam memperbaiki kesalahan bacaan. ${ }^{17}$

5) Mengulang hafalan Alquran dengan metode maqra'ah.

Mengulang hafalan dengan cara ini, yaitu para penghafal Alquran membuat lingkaran atau disebut halaqah. Setiap penghafal membaca beberapa ayat atau surah secara bergantian hingga selesai. Metode ini dilakukan selama satu jam dan diadakan setiap hari.

6) Mengulang hafalan sebelum tidur.

Waktu ideal untuk mengulang hafalan adalah sore hari. Ahli psikologi menyebutkan bahwa 45 menit sebelum tidur adalah waktu terbaik. Sebelum tidur para penghafal Alquran dianjurkan mengulang hafalannya karena waktu ini sangat efektif dan produktif. ${ }^{18}$

7) Mengulang hafalan ayat-ayat yang mirip.

Salah satu kendala yang dihadapi penghafal qur'an yaitu, ayat-ayat yang serupa, terkadang perbedaan antara kedua ayat hanya satu huruf, baik diawal,tengah atau akhir ayat. Oleh karena itu para penghafal harus membaca ayat-ayat tersebut secara berulang-ulang sekaligus mengingat setiap tempatnya. Ayat-ayat serupa ini dalam bahasa arab disebut dengan mutasyabihat.

8) Mengulang hafalan dengan mendengar MP3 dan mushaf digital.

Dalam proses mengulang hafalan penghafal bisa mengulang dengan MP3 Alquran. Usahakan fokus pada satu qari' ketika mengulang agar hafalan meresap dan mudah diingat.

9) Wirid Alquran.

Yang dimaksud dengan wirid Alquran yaitu mengulang hafalan Alquran setelah melakukan sholat rawatib. Wirid Alquran dilakukan setelah zikir sholat. Minimal dilakukan dalam 2 waktu sholat saja dalam sehari misalnya sholat ashar atau maghrib. Pengulangan dilakukan sesuai kemampuan penghafal.

13 Dinda Fitria, Penerapan Metode Muraja'ah dalam Menghafal Alquran Peserta Didik SDIQU AlBahjah 03 Karangrejo Tulungagung", (online), Available, http://repo.iain-tulungagung.ac.id, diakses pada tanggal 28 September 2019.

${ }^{14}$ Adi Hiadayat, Muslim Zaman Now 30 Hari hafal Alqur'an Metode At-Taisir, (Bekasi: Institut Quantum Akhyar, 2018), hlm. 25.

${ }^{15}$ Wiwi Alawiyah Wahid, Panduan Menghafal Alquran Super Kilat, hlm. 75-77.

16 Wiwi Alawiyah Wahid, Cara Cepat Bisa Menghafal Alquran..., hlm. 100.

17 Rachmat Morado Sugiarto, Cara Gampang Menghafal Alquran..., hlm. 74-75.

${ }^{18}$ Rachmat Morado Sugiarto, Cara Gampang Menghafal Alquran..., hlm. 75-76. 
10) Mengulang hafalan kapanpun ada kesempatan

Hal ini bisa dilakukan bagi orang sibuk yang tidak memiliki waktu khusus untuk mengulang hafalan karena banyaknya pekerjaan. Dalam kasus seperti ini, penghafal hendaknya menggunakan kesempatan waktu yang dimilikinya untuk mengulang hafalan. ${ }^{19}$

Didalam buku yang ditulis oleh Amjad Qosim juga disebutkan bahwa ada berapa metode dalam melakukan muroja'ah, antara lain:

1) Takhmis Alquran, artinya menghatamkan hafalan setiap lima harisekali. Seorang ahli ilmu berkata, "siapa yang menghatamkan muraja'ah hafalannya selama lima hari, dia tidak akan lupa."

2) Tasbi' Alquran, yaitu meng-hatamkan Alquran setiap seminggu sekali.

3) Meng-hatamkan Alquran setiap sepuluh hari sekali

4) Menghususkan dan mengulang-ulang (satu juz) selama seminggu sambil terus melakukan muraja'ah secara umum.

5) Menghatamkan muraja'ah hafalan Alquran setiap sebulan sekali

6) Menghatamkan dengan dua metode, ini yang paling baik. Pertama, dengan menggunakan metode kelima, yaitu menghatamkan muraja'ah setiap bulan. Kedua, menghafal dengan menggunakan metode ke empat, yaitu berkonsentrasi terhadap juz tertentu.

7) Menghatamkan saat shalat (ketika berdiri membaca ayat, atau ketika sholat belum dimulai atau sesudah sholat dilaksanakan).

8) Konsentrasi melakukan muraja'ah 5 juz terlebih dahulu dan mengulang-ulang pada waktu yang ditentukan. ${ }^{20}$

Dari beberapa metode yang dijelaskan diatas, ada beberapa tekhnik dalam mengulang hafalan, yaitu dengan membagi-bagi Alquran menjadi beberapa hizb (tahzib). Merujuk kepada hadits Aus bin Hudzaifah rodiallahuanhu dia berkata: "aku bertanya kepada para sahabat Rasulullah Sallallahu 'Alaihi Wasallam tentang bagaimana mereka membagi-bagi Alquran (tahzib,) mereka menjawab: "tiga, lima, tujuh, sembilan, sebelas, dan tigabelas, serta hizbAl-Mufashal dari surah (qof) sampai khatam (selesai)." (HR. Ahmad). Itu artinya pada hari pertama (muraja'ah) tiga surat, hari kedua lima surat, hari ketiga tujuh surat dan seterusnya. ${ }^{21}$

b. Prinsip Muraja'ah Alquran

Kegiatan mengulang hafalan sangat menjaga hafalan dari hilang dan terlepas. Mengulang ada dua bentuk, yaitu: Mengulang bacaan dengan cara membatin secara rahasia, mengulang-ulang dengan suara keras. ${ }^{22}$ Jadi, fungsi dari mengulang-ngulang dengan keras ini agar yang menyimak dapat mengetahui kesalahan hafalan kita, selain itu jika kita mengulang-ngulang dengan keras maka makhraj dan tajwidnya akan terdengar jelas.

\section{Pengertian Program Tahfidzul Qur'an}

Secara umum, program diartikan sebagai rencana atau rancangan kegiatan yang akan dilakukan. Sedangkan program secara khusus adalah suatu unit atau kesatuan kegiatan yang merupakan realisasi atau implementasi dari suatu kebijakan, berlangsung dalam proses yang berkesinambungan, dan terjadi dalam suatu organisasi yang melibatkan sekelompok orang. ${ }^{23}$

Tahfidzul atau menghafal berasal dari kata dasar hafal yang dari bahasa Arab hafidza-yahfadzuhifdzan, yaitu lawan dari lupa, selalu ingat dan sedikit lupa. ${ }^{24}$ Kata menghafal dapat juga disebut sebagai memori, dimana apabila mempelajarinya maka membawa kita pada psikologi kognitif, terutama pada model manusia sebagai pengolah informasi. Adapun di dalam bukunya Sa'dulloh menyebutkan ada tiga tahapan ingatan atau menghafal yaitu:

\section{a. Encoding (memasukkan Informasi kedalam ingatan)}

70-81.

${ }^{19}$ Rachmat Morado Sugiarto, Cara Gampang Menghafal Alquran, (Jakarta: Wahyu Qalbu, 2019), hlm.

${ }^{20}$ Amjad Qasim, Hafal Alquran dalam Sebulan, (Solo: Qiblat Press, 2010), hlm. 162-163.

${ }^{21}$ Yahya Abdul Fattah Az-Zawawi, Revolusi Menghafal Alquran, (Surakarta: Insan Kamil, 2015), hlm.

106.

22 Ghausani Yahya, Juz 29,30.

${ }^{23}$ Suharsimi Arikunto, Evaluasi Program Pendidikan, (Jakarta: Bumi Aksara, 2007), hlm. 2.

${ }^{24}$ Mahmud Yunus, Kamus Arab-Indonesia, (Jakarta : Hidakarya Agung, 1990), hlm, 105. 
Encoding adalah suatu proses memasukkan informasi ke dalam ingatan. Proses ini melalui dua alat indra manusia, yaitu penglihatan dan pendengaran. Kedua alat indra ini memegang peranan penting dalam penerimaan informasi sebagaimana banyak dijelaskan dalam Alquran, dimana penyebutan mata dan telinga selalu beriringan (as-sam'a wal abshar).

b. Storage ( penyimpanan)

Storage adalah penyimpanan informasi yang masuk di dalam gudang memori. Gudang memori terletak di dalam memori jangka panjang (long term memory). ${ }^{25}$

c. Retrieval (pengungkapan kembali)

Retrieval adalah pengungkapan kembali (repoduksi) informasi yang telah disimpan di dalam gudang memori adakalanya serta merta dan ada kalanya perlu pancingan. Dalam proses menghafal Alquran urutan-urutan ayat sebelumnya secara otomatis menjadi pancingan terhadap ayat-ayat selanjutnya. ${ }^{26}$

\section{Adab Menghafal}

Imam An-Nawawi menjelaskan ada beberapa adab utama para penghafal Alquran. Diantaranya yaitu, Ikhlas, membersihkan mulut dengan bersiwak, dalam keadaan suci, tempat yang bersih, memulai dengan membaca $t a$ 'awudz, membiasakan mengawali setiap surah dengan Bismillah, mentadaburi ayat. Jangan terburu-buru untuk menambah hafalan, konsisten dengan satu mushaf Alquran, tulislah apa yang anda hafal serta kenali tempat kesalahannya, ulangi apa yang telahdihafal, pada hari berikutnya, bacalah apa yang telah hafal di luar kepala sekali lagi sebelum memulai hafalan baru, jadikan satu hari dalam seminggu untuk mengulang-ulang apa yang telah anda hafal selama satu minggu itu. ${ }^{27}$

\section{Waktu yang Tepat Untuk Menghafal Alquran}

Membaca Alquran atau menghafal Alquran sebenarnya tidak ada batasan waktu. Artinya kapan pun bisa dibaca atau dihafalkan. Hal terpenting ialah dalam keadaan suci dari hadas besar dan kecil. Tetapi tidak ada salahnya jika membaca dan menghafal Alquran pada waktu yang dianggap sesuai dan baik agar mudah menghafal dan memahami ayat yang terkandung secara maksimal dan membekas dalam jiwa kemudian dapat diamalkan dalam kehidupan sehari-hari. ${ }^{28}$

Dalam kitab At-Tibyan fi Adabi Hamalati Alquran karya imam An-Nawawi dijelaskan bahwa mazhab Syafi'i dan mazhab yang lain berpendapat, waktu terbaik untuk mebaca Alquran ialah ketika shalat. Karena memperlama berdiri dalam shalat itu lebih utama dari sujud dan gerakan lain. Sedangkan waktu yang baik untuk membaca Alquran di luar shalat adalah sebagai berikut: ${ }^{29}$

a. Sepertiga Malam

Pada waktu ini sangat baik untuk membaca atau menghafal Alquran, baik saat shalat tahajjud maupun setelahnya. Karena, pada saat itu otak masih segar dan akan lebih konsentrasi maka akan terasa khusyuk dan berkesan dalam membaca dan menghafal. Hal in sesuai dengan firman Allah dalam surat Al-Muzammil ayat 6 yang artinya "sesungguhnya bangun di waktu malam adalah lebih tepat (untuk khusyuk) dan bacaan di waktu itu lebih berkesan". ${ }^{30}$

b. Setelah Fajar Sampai Terbit Matahari

Waktu setelah fajar ini juga baik untuk membaca dan menghafal Alquran, karena semua anggota badan telah istirahat panjang, dan pada umumnya saat-saat seperti ini orang-orang belum memulai tugas-tugas berat.

c. Setelah Tidur Siang

Tidur siang dapat mengembalikan kesegaran badan setelah diisi dengan beban ketika bekerja keras. Oleh karena itu, setelah tidur siang, kondisi badan sudah segar kembali dan bisa dimanfaatkan sekedar untuk menambah atu mengualang hafalan.

d. Usai Shalat

Sempatkan 30 menit atau satu jam setelah shalat untuk berdiam diri diatas sajadah untuk membaca atau mengulang hafalan, karena rasa semangat untuk melakukan pengulangan masih ada. Waktu

\footnotetext{
${ }^{25}$ Sa'dulloh, 9 Cara Praktis Menghafal Al-Qur'an, (Jakarta: Gema Insani, 2008), hlm. 47.

${ }^{26}$ Ibid,. hlm. 50.

${ }^{27}$ Ahmad Salim Badwilan, Panduan Cepat..., hlm. 117-118.

${ }^{28}$ Rofiul Wahyudi \& Ridhoul Wahidi, Metode Cepat Hafal Al-Qur'an Saat Sibuk Kuliah, (Yogyakarta: Semesta Hikmah,2017), hlm. 79.

${ }^{29}$ Ibid., hlm 79.

${ }^{30}$ Ibid, . hlm 80.
} 
tersebut merupakan salah satu waktu yang mustajab dan jika mau sedikit saja menyempatkan waktu untuk menambah atau mengulang, insyaallah akan ada ketenangan dalam jiwa. ${ }^{31}$

e. Antara Magrib dan Isya'

Sudah menjadi tradisi umat Islam di Indonesia setiap setelah magrib selalu membiasakan untuk membaca Alquran. Tradisi ini juga dilakukan oleh para penghafal Alquran.

\section{Penerapan Metode Tasmi' dan Muraja'ah dalam Program Tahfidzul Qur'an Pada Santriwati Ma'had Tahfidz Hidayatul Qur'an Desa Puding Besar}

Menghafal Alquran merupakan suatu program unggulan yang diikuti oleh seluruh santri dan santriwati, sekaligus ustadz ustadzah yang ada di Ma'had Tahfidz Hidayatul Quran. Tahfidzul qur'an merupakan suatu kegiatan proses menghafal Alquran dengan melantunkan ayat demi ayat tanpa melihat mushaf Alquran. Adapun yang dimaksud dengan program tahfidzul qur'an yang ada di Ma'had Tahfidz Hidayatul Qur'an ialah proses menghafal untuk mencapai hafalan 30 juz mutqin.

Ma'had Tahfidz Hidayatul Qur'an melaksanakan kegiatan pembelajaran tahfidz Alquran dengan visi dan misi untuk membentuk generasi qurani, yang berpedoman pada Alquran dalam menjalankan segala aktivitasnya. Oleh karena itu untuk mencapai cita-cita tersebut maka dilakukan program unggulan yaitu tahfidzul qur'an.

Sebelum memasuki pembahasan mengenai metode yang digunakan, peneliti akan memaparkan hasil wawancara yang peneliti lakukan dengan ustadzah pembimbing tahfidz dan beberapa santriwati sekaligus observasinya. Adapun metode tasmi' yaitu mensetorkan hafalan secara rutin kepada pembimbing tahfidz atau kepada seorang teman. Tujuan men-tasmi'kan hafalan agar dapat diketahui letak kesalahan dan dapat langsung diperbaiki kesalahan dalam hafalan tersebut. Dalam program tahfidz santriwati men-tasmi'kan hafalan yang baru dan hafalan muraja'ah. ${ }^{32}$ Waktu yang digunakan untuk mentasmi'kan hafalan yaitu $b a^{\prime} d a$ subuh, qobla dhuhah, dan $b a^{\prime} d a$ magrib. Santriwati menghafal sebanyak 1 halaman untuk hafalan baru dan 2 halaman muraja'ah, 1 halaman baru ditasmi'kan ba'da subuh sedangkan 2 halaman muraja'ah ditasmi'kan qobla dhuha, kemudian ba'da maghrib men-tasmi'kan hafalan paginya 3 halaman sealigus. ${ }^{33}$

Sedangkan untuk santriwati yang sudah mencapai target hafalan maka mereka berhenti menghafal halaman yang baru, difokuskan untuk muraja'ah hafalan kemudian ditasmi'kan lagi kepada guru minimal 3 halaman satu kali duduk, dilakukan sampai kepada hafalan terakhir yang dimiliki. ${ }^{34}$

\section{Kesimpulan}

Setelah menyajikan uraian yang ditampilkan di beberapa bagian dan menganalisis secara terpadu, maka penulis akan mengambil beberapa kesimpulan sebagai akhir hasil dari penelitian ini. Untuk lebih jelasnya maka penulis memaparkan sebagai berikut:

Proses penerapan metode tasmi' dan muraja'ah yang diterapkan di Ma'had Tahfidz Hidayatul Qur'an dalam program tahfidzul qur'an pada sanrtiwati yaitu pada metode tasmi' ada tasmi' perorangan, di mana santriwati mentasmi'kan hafalannya maju ke depan sendiri-sendiri secara bergantian untuk mentasmi'kan hafalan kepada ustadzah pembimbing. Waktu tasmi' terbagi dalam 3 waktu, yaitu setelah subuh, qobla dhuha, dan ba'da magrib. Pada waktu subuh dan qobla dhuha men-tasmi'kan hafalan baru, magrib men-tasmi'kan hafalan lama, yaitu 2 halaman hafalan kemarin dan 1 halaman yang ditasmi'kan pada waktu subuh atau qobla dhuha. Sebelum men-tasmi'kan hafalan kepada ustadzah, santriwati biasanya terlebih dahulu men-tasmi'kan hafalan kepada sesama teman tahfidz dan kepada keluarga ketika kunjungan, agar orang tua bisa mengetahui perkembangan hafalan anaknya.

Metode muraja'ah yang diterapkan di Ma'had Tahfidz Hidayatul Qur'an, santriwati yang sudah memiliki hafalan harus memuraja'ahkan setiap waktu, baik ketika di kelas, waktu luang atau sebelum tidur. Hafalan tersebut ditasmi'kan pada waktu qobla dhuha dan magrib. Setiap santriwati yang sudah menyelesaikan hafalan 1 juz santriwati berhenti 4 hari untuk mempersiapkan hafalan tersebut dan men-tasmi'kan kembali 1 juz dalam satu kali duduk. Kemudian bagi santriwati yang sudah mencapai 5 juz maka berhenti

${ }^{31}$ Ibid., hlm. 81.

32 Hamda, Pembimbing Tahfidz, Ma'had Tahfidz Hdayatul Qur'an Desa Puding Besar, Wawancara tanggal 05 Agustus 2019.

${ }^{33}$ Sunnyah, Santriwati Ma'had Tahfidz Hidayatul Qur'an Desa Puding Besar, Wawancara tanggal 05 Agustus 2019.

2019.

${ }^{34}$ Kegiatan Santriwati di Ma'had Tahfidz Hidayatul Qur'an Desa Puding Besar, Observasi, 05 Agustus 
1 sampai 2 minggu untuk mempersiapkan hafalan yang akan ditasmi'kan, yaitu 5 juz dalam satu kali duduk di depan ustadzah dan santriwati lainnya.

Penerapan metode tasmi' di Ma'had Tahfidz Hidayatul Qur'an Desa Puding Besar berhasil diterapkan. Hal ini dapat dilihat dari banyaknya santriwati yang hafal dan mencapai target yang ditentukan, bahkan ada yang melebihi pencapaian target. Begitu pula dengan metode muraja'ah santriwati mampu mentasmi'kan kembali hafalan muraja'ah baik kepada ustadzah pembimbing atau ustadzah penguji ujian tahfidz. Hal ini terbukti dari hasil yang diperoleh santriwati dengan kategori penilaian mumtaz (kesalahan 0-1), jayyid jiddan (kesalahan 2-4), jayyid (kesalahan 5-7), maqbul (kesalahan 8-10), rasib (kesalahan lebih dari sepeluh), dari kelima penilaian tersebut kebanyakan santriwati mendapatkan nilai jayyid jiddan, jayyid, dan mumtaz.

Sehingga dapat disimpulkan bahwa metode tasmi' dan muraja'ah berhasil diterapkan dalam program tahfidzul qur'an pada Santriwati Ma'had Tahfidz Hidayatul Qur'an Desa Puding Besar.

\section{Referensi}

Al Hafidz, Ahsin W. 2000. Bimbingan Praktis Menghafal Alquran. Jakarta: Bumi Aksara. Arikunto, Suharsimi. 2007. Evaluasi Program Pendidikan. Jakarta: Bumi Aksara. Az-Zawawi, Yahya Abdul Fattah. 2015. Revolusi Menghafal Alquran. Surakarta: Insan Kamil.

Fitria, Dinda. 2017. "Penerapan Metode Muraja'ah dalam menghafal Alqura n Peserta Didik SDIQu Al Bahjah 03 Karangrejo Tulungagung" (online) available:http://repo.iain-tulungagung.ac.id. Diakses pada tanggal 28 September 2019.

Hidayat, Adi. 2018. Muslim Zaman Now 30 hari hafal Alquran Metode At Taisir. Bekasi: Institut Quantum Akhyar.

Ibnu Rusyd, Raisya Maula. 2019. Panduan Praktis dan Lengkap Tahsin dan Tajwid Tahfidz Untuk Pemula. Yogyakarta: Laksana.

Mahfudhon, Ulin Nuha . 2017. Jalan Penghafal Alquran. Jakarta: Kompas Gramedia.

Massul, Romdoni. 2014 Metode Cepat Menghafal \& Memahami Ayat-ayat suci Alquran. Yogyakarta: Lafal Indonesia.

Qosim, Amjad. 2010. Hafal Alquran dalam Sebulan. Solo: Qiblat Press.

Sa'dulloh. 2008. 9 Cara Praktis Menghafal Alquran. Jakarta: Gema Insani.

Sugiarto, Rachmat Morado. 2019. Cara Gampang Menghafal Alquran. Jakarta: Wahyu Qolbu.

Wahid, Wiwi Alawiyah. 2014. Cara Cepat Bisa Menghafal Alquran. Yogyakarta: Diva Prees.

Wahyudi, Rofiul \& Ridhoul Wahidi. 2017. Metode Cepat Hafal Al-Qur'an Saat Sibuk Kuliyah. Yogyakarta: Semesta Hikmah.

Yunus, Mahmud. 2010. Kamus Arab-Indonesia. PT Mahmud Yunus Wa Dzurriyah.

Zawawie, Mukhlisoh. 2011. PM3 Alquran Pedoman Membaca, Mendengar, dan Menghafal Alquran. Solo: Tinta Medina.. 